\title{
Endoscopic salvage technique for spontaneous dis- location and tumor ingrowth of a partially covered, self-expandable metallic stent after endoscopic ultrasound-guided choledochoduodenostomy
}

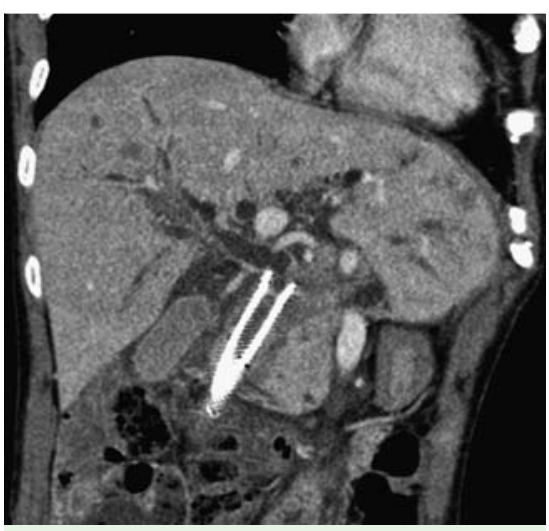

Fig. 1 Radiograph 7 months after endoscopic ultrasound-guided choledochoduodenostomy in a 67-year-old woman, showing spontaneous dislocation of a partially covered self-expandable metallic stent.

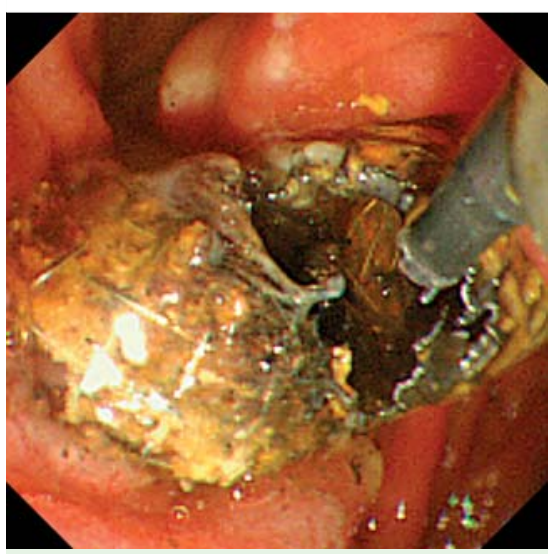

Fig. 2 Endoscopic image 7 months after endoscopic ultrasound-guided choledochoduodenostomy showing the partially covered self-expandable metallic stent trimmed using argon plasma coagulation.

Endoscopic ultrasound-guided choledochoduodenostomy (EUS-CDS) has been established as an alternative method of biliary drainage after failure of endoscopic retrograde cholangiopancreatography (ERCP) [1,2]. Because of its prolonged stent patency and reduced bile leakage, use of the covered self-expandable metallic stent (CSEMS) has recently been favored. We present a case of spontaneous dislocation of a partially covered SEMS (PCSEMS) after EUS-CDS that was successfully rescued by endoscopic intervention.

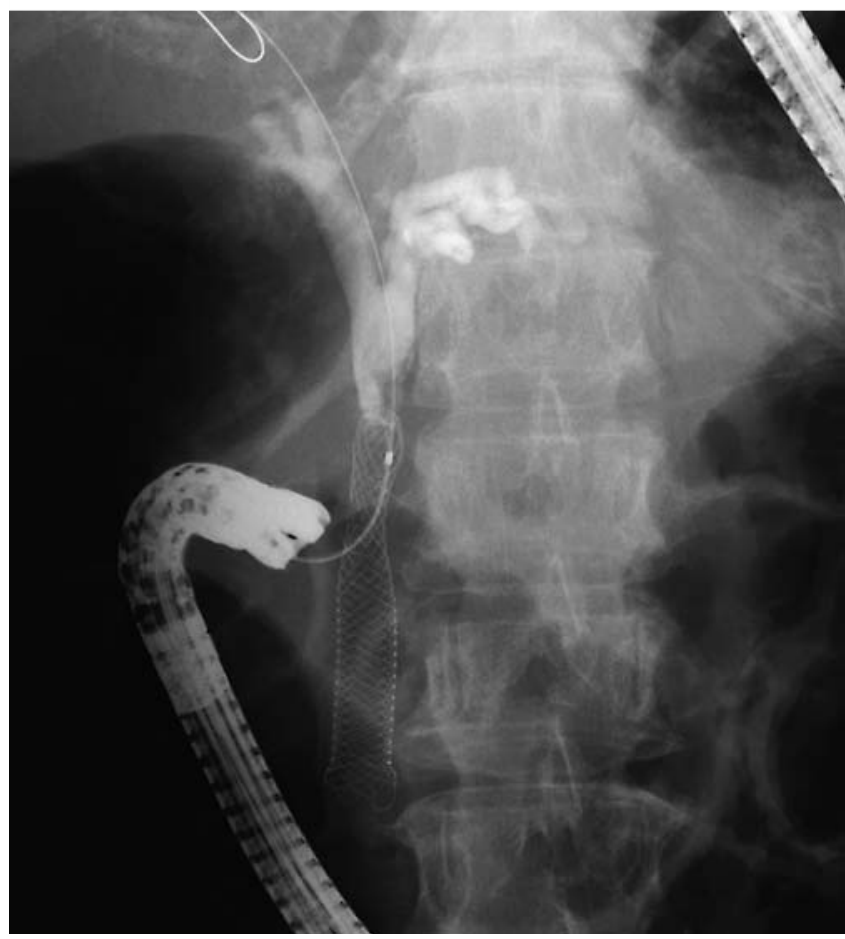

Fig. 3 Radiograph showing spontaneous dislocation of the partially covered selfexpandable metallic stent and stricture of the stent due to tumor ingrowth.

A 67-year-old woman with metastatic cancer of the pancreatic head was admitted to our hospital with obstructive jaundice. She underwent EUS-CDS using a PCSEMS (WallFlex stent, $10 \times 60$ mm; Boston Scientific Japan, Tokyo, Japan) without complication ( Video 1). Seven months later, she developed acute cholangitis. The PCSEMS had dislocated, as was confirmed on computed tomography ( $\bullet$ Fig. 1 ). Our first attempt was to try to extract the PCSEMS using a snare, but this failed because of tumor ingrowth into the uncovered portion. In our next attempt, the PCSEMS was partially trimmed using argon plasma coagulation with an electrosurgical generator (ICC 200; Erbe Elektromedizin, Tübingen, Germany) at $80 \mathrm{~W}$ and with a flow rate of $2 \mathrm{~L} / \mathrm{min}$ ( Fig. 2 ), and we attempted guidewire cannulation through the partially fragmented PCSEMS. A 0.025-inch guidewire was advanced through the ERCP catheter under fluoroscopic guidance ( Video 2 ). ERC revealed a stricture of the PCSEMS caused by tumor ingrowth ( Fig.3, Video 2). An ERCP catheter and a biliary dilation catheter could not be passed through the stricture $(\bullet$ Video 2). In our third attempt, we dilated the stricture using a 6-Fr wireguided diathermic dilator (Cysto-GastroSet; Endo-Flex, Voerde, Germany) using an EGS-100 electrosurgical generator (Olympus, Tokyo, Japan; 30W in pulse cut slow mode) ( Fig. 4, Video 2). Finally, a 6-Fr uncovered SEMS (Zilver 635 stent; $10 \mathrm{~mm} \times 60 \mathrm{~mm}$, Cook-Japan, Tokyo, Japan) was placed without complication $(\checkmark$ Fig. 5, Video 2).

\section{Video 1}

Endoscopic ultrasound-guided choledochoduodenostomy using a partially covered selfexpandable metallic stent.

\section{Video 2}

Endoscopic salvage technique for a severe stricture of a partially covered self-expandable metallic stent that was dilated using a 6-Fr diathermic dilator, followed by placement of an uncovered self-expandable metallic stent. 


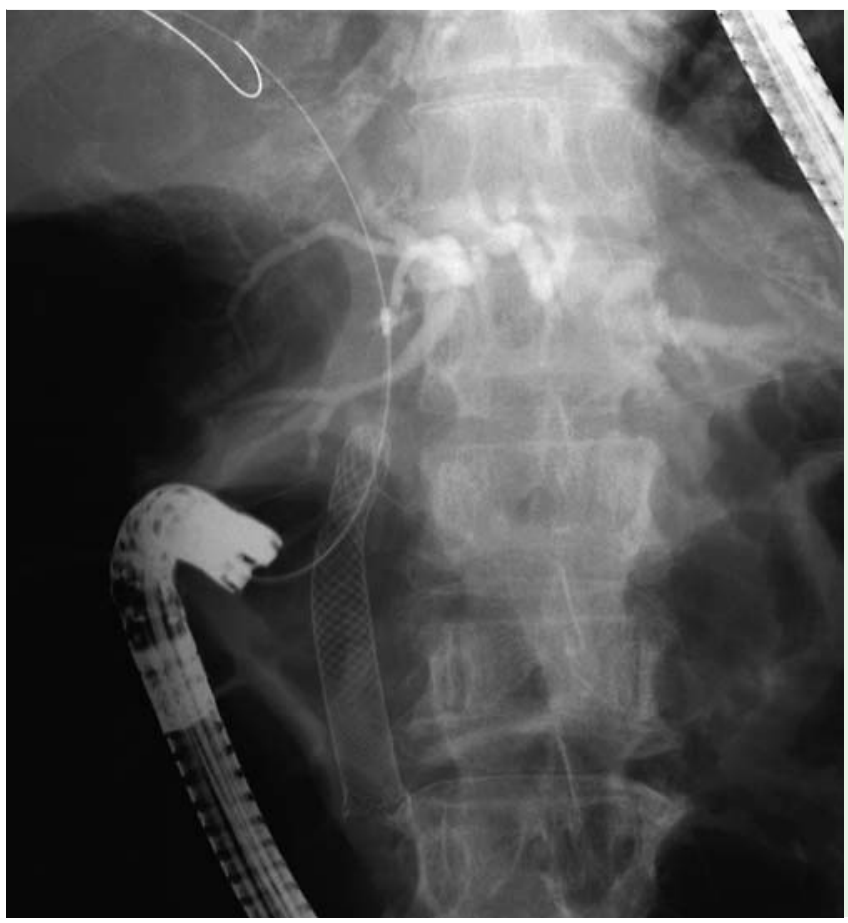

Fig.4 Radiograph showing a 6-Fr diathermic dilator successfully advanced through the severe stricture over a guidewire under fluoroscopic guidance.

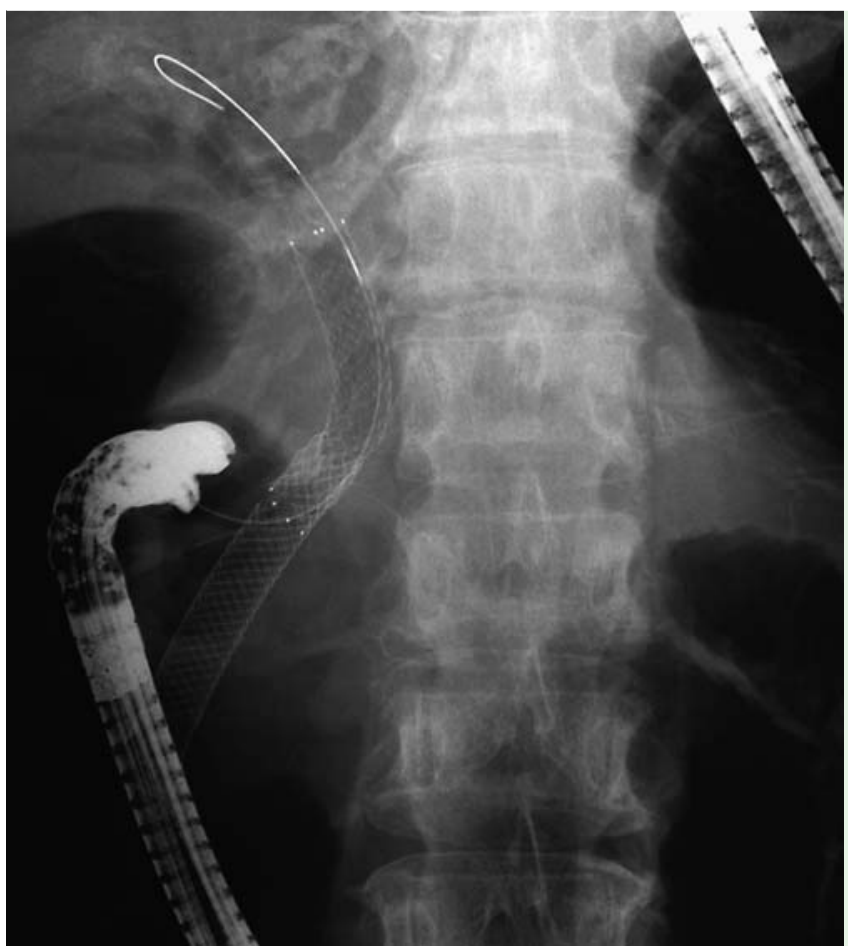

Fig. 5 Radiograph showing placement of the uncovered selfexpandable metallic stent in the stricture.

Spontaneous dislocation of a PCSEMS after EUS-CDS is a very rare complication $[1,2]$. In the case described here, we successfully mitigated this situation using endoscopic intervention. In particular, a diathermic dilator is useful for dilating severe strictures $[3,4]$. The findings described here suggest that more attention should be paid to the possibility of PCSEMS dislocation when performing EUS-CDS.
Endoscopy_UCTN_Code_CPL_1AL_2AD

\section{Competing interests: None}

\section{Hiroshi Kawakami, Masaki Kuwatani, Kazumichi Kawakubo, Taiki Kudo, Yoko Abe, Kimitoshi Kubo, Naoya Sakamoto}

Department of Gastroenterology and Hepatology, Hokkaido University Graduate School of Medicine, Sapporo, Japan

\section{References}

1 Itoi T, Isayama H, Sofuni A et al. Stent selection and tips on placement technique of EUS-guided biliary drainage: transduodenal and transgastric stenting. J Hepatobiliary Pancreat Sci 2011; 18: 664-672

2 Kawakubo K, Isayama $H$, Kato $H$ et al. Multicenter retrospective study of endoscopic ultrasound-guided biliary drainage (EUS-BD) for malignant biliary obstruction in Japan. J Hepatobiliary Pancreat Sci 11. 09. 2013. doi: doi: 10.1002/jhbp.27 [Epub ahead of print]

3 Kawakami H, Kuwatani M, Eto K et al. Resolution of a refractory severe biliary stricture using a diathermic sheath. Endoscopy 2012; 44 (Suppl. 02): E119-120

4 Kawakami H, Kuwatani M, Kawakubo Ket al Transpapillary dilation of refractory severe biliary stricture or main pancreatic duct by using a wire-guided diathermic dilator (with video). Gastrointest Endosc 07. 09. 2013. doi: 10.1016/j.gie.2013.07.055 [Epub ahead of print]

Bibliography

DOI http://dx.doi.org/

10.1055/s-0033-1359163

Endoscopy 2014; 46: E58-E59

(C) Georg Thieme Verlag KG

Stuttgart · New York

ISSN 0013-726X

\section{Corresponding author}

\section{Hiroshi Kawakami, MD, PhD}

Department of Gastroenterology and Hepatology Hokkaido University Graduate School of Medicine Kita 15, Nishi 7, Kita-ku

Sapporo 060-8638

Japan

Fax: +81-11-7067867

hiropon@med.hokudai.ac.jp 